\title{
Aflatoxin compromises development of the preimplantation bovine embryo through mechanisms independent of reactive oxygen production
}

\author{
Y. Jiang, P. J. Hansen, Y. Xiao, T. F. Amaral, D. Vyas, and A. T. Adesogan* \\ Department of Animal Sciences, University of Florida, Gainesville 32611
}

\section{ABSTRACT}

Aflatoxin is a potent carcinogen often found in animal feedstuffs. Although it reportedly impairs development of the preimplantation pig embryo, it is not known whether it adversely affects development of the preimplantation bovine embryo. We conducted 3 experiments to investigate this possibility and determine whether deleterious effects of aflatoxin were caused by increased production of reactive oxygen species (ROS). Experiments were conducted with embryos produced in vitro and cultured after fertilization with various concentrations of aflatoxin. For experiment 1, embryos were treated with 0 (control), 40, 400, or $4,000 \mu \mathrm{g} / \mathrm{L}$ of aflatoxin $\mathrm{B}_{1}\left(\mathrm{AFB}_{1}\right)$. Treatment at all concentrations of $\mathrm{AFB}_{1}$ tended to reduce cleavage rate, with the 2 highest concentrations having significant effects. As compared with the control, $40 \mu \mathrm{g} / \mathrm{L} \mathrm{AFB}_{1}$ reduced the percentage of oocytes becoming blastocysts and the percentage of cleaved embryos becoming blastocysts (19.7 vs. 8.1\% and 30.3 vs. $14.3 \%$, respectively). Complete inhibition of blastocyst formation occurred at concentrations of 400 and $4,000 \mu \mathrm{g} / \mathrm{L}$ of $\mathrm{AFB}_{1}$. Experiments 2 and 3 involved a $2 \times 2$ factorial design with effects of $\mathrm{AFB}_{1}$ $(0$ and $40 \mu \mathrm{g} / \mathrm{L}$ ), the antioxidant Trolox (6-hydroxy2,5,7,8-tetramethylchroman-2-carboxylic acid, a watersoluble analog of vitamin $\mathrm{E}$; 0 and $5 \mu M$ ), and their interaction on production of ROS in putative zygotes (experiment 2) and development to the blastocyst stage (experiment 3). Production of ROS was increased by $\mathrm{AFB}_{1}$, and this effect was reversed by Trolox. However, Trolox did not prevent the reduction in development to the blastocyst stage caused by $\mathrm{AFB}_{1}$. Thus, the antidevelopmental effects of $\mathrm{AFB}_{1}$ are not caused solely by increased ROS production. Rather, other underlying mechanisms exist for the adverse effects of aflatoxin

Received April 21, 2019.

Accepted July 11, 2019.

*Corresponding author: adesogan@ufl.edu on embryonic development. Overall, results indicate the potential for feeding aflatoxin-contaminated feed to cause embryonic loss in cattle.

Key words: aflatoxin, antioxidant, reactive oxygen species, embryonic development

\section{INTRODUCTION}

Aflatoxins, a group of secondary metabolites mainly produced by the fungal species Aspergillus flavus and Aspergillus parasiticus, are one of the most carcinogenic substances identified (Frisvad et al., 2005). An intercontinental survey reported that $33 \%$ of feedstuff samples were contaminated with aflatoxin, with up to $2,454 \mu \mathrm{g} / \mathrm{kg}$ detected in finished feeds (Rodrigues and Naehrer, 2012). A survey conducted in Tunisia showed that $55 \%$ of plasma samples from lactating cows contained aflatoxin $\mathrm{B}_{1}\left(\mathbf{A F B}_{1}\right.$; Abbès et al., 2012). Among other effects, consumption of feedstuffs contaminated with aflatoxins can reduce milk production in dairy cows, decrease milk quality and safety, reduce feed efficiency in beef cattle, and compromise immune and ruminal functions (Ogunade et al., 2018). In addition, $\mathrm{AFB}_{1}$ can reduce viability and DNA integrity of bull sperm (Komsky-Elbaz et al., 2018), disrupt maturation of the porcine oocyte (Liu et al., 2015), and cause DNA damage to the porcine preimplantation embryo (Shin et al., 2018). However, it is not known whether aflatoxin can compromise female fertility of dairy cows.

Our first objective in the current study was to examine whether development of the preimplantation embryo would be compromised by exposure to $\mathrm{AFB}_{1}$. We hypothesized that $\mathrm{AFB}_{1}$ would compromise preimplantation development at concentrations similar to those found in the tissues of animals consuming contaminated feed. Aflatoxin $\mathrm{B}_{1}$ was tested rather than other aflatoxin metabolites such as aflatoxin $\mathrm{M}_{1}$ $\left(\mathrm{AFM}_{1}\right)$ because $\mathrm{AFB}_{1}$ is one of the most prevalent aflatoxins present in animal feeds (Han et al., 2013) and data on concentrations of $\mathrm{AFM}_{1}$ in blood and tissue are limited. The lowest concentration of $\mathrm{AFB}_{1}$ tested (40 $\mu \mathrm{g} / \mathrm{L}$ ) was chosen based on previous studies that re- 
ported a wide range of aflatoxin concentrations present in plasma and tissues of cattle, with up to $56.6 \mu \mathrm{g} / \mathrm{kg}$ being detected (Stubblefield et al., 1983). Our second objective was to determine the role of reactive oxygen species (ROS) in the deleterious actions of $\mathrm{AFB}_{1}$. We hypothesized that adverse effects of $\mathrm{AFB}_{1}$ involved ROS because aflatoxins can increase ROS production by cells (Shen et al., 1996; Mehrzad et al., 2011; Liu and Wang, 2016; Shin et al., 2018) and because exposure to conditions that increase oxidative stress can compromise the ability of the preimplantation bovine embryo to develop to the blastocyst stage (Moss et al., 2009; Takahashi et al., 2016). To test the hypothesis, we measured ROS production by embryos treated with $\mathrm{AFB}_{1}$. We also evaluated whether inhibition of ROS with Trolox, a water-soluble version of vitamin $\mathrm{E}$ that can react with free radicals and prevent oxidative damage (Nimse and Pal, 2015), could block the deleterious effects of $\mathrm{AFB}_{1}$ on development. Previously, Trolox was found to prevent overproduction of ROS and the antidevelopmental effects of menadione on preimplantation bovine embryos (Moss et al., 2009).

\section{MATERIALS AND METHODS}

\section{In Vitro Production of Embryos}

Bovine ovaries were collected from a local abattoir and transported in $0.9 \%$ (wt/vol) $\mathrm{NaCl}$ (saline) to the laboratory at $23^{\circ} \mathrm{C}$ to arrive within $8 \mathrm{~h}$. Ovaries with greater than 10 follicles on the surface were selected for harvesting of cumulus-oocyte complexes. The ovaries were washed 3 times with saline and, after the follicular fluid from large (>10 mm diameter) follicles was discarded, the surface of the ovary was sliced with a scalpel and the ovary vigorously swirled in a beaker containing $100 \mathrm{~mL}$ oocyte washing medium (MOFA Global, Verona, WI). The mixture was then filtered through a 100- $\mu \mathrm{m}$ Falcon cell strainer (Fisher Scientific, Hampton, NH). Subsequently, the material retained on the strainer was washed 3 times with $20 \mathrm{~mL}$ of oocyte washing medium using a $10-\mathrm{mL}$ syringe connected to a needle. The cellular material was washed from the strainer into a 100-mm grid plate, and cumulus-oocyte complexes were harvested using a Wiretrol pipette (Drummond Scientific, Broomall, PA) and a dissecting microscope.

Oocytes with $\geq 3$ layers of cumulus cells were selected and cultured in groups of 10 in $50-\mu \mathrm{L}$ microdrops of in vitro maturation medium (IVF Bioscience, Falmouth, UK) covered with mineral oil (Sigma-Aldrich, St. Louis, MO). Maturation of oocytes proceeded for
$22 \mathrm{~h}$ at $38.5^{\circ} \mathrm{C}$ in an atmosphere of $5 \%$ (vol/vol) $\mathrm{CO}_{2}$ in humidified air. Matured oocytes were washed 3 times with HEPES-TALP solution (Tyrode's albumin lactate pyruvate; Ortega et al., 2016) and transferred to a fertilization dish containing $1.7 \mathrm{~mL}$ of IVF-TALP fertilization medium (Ortega et al., 2016). Sperm were prepared using a gradient of Puresperm (Nidacon, Gothenburg, Sweden) from 3 straws of frozen semen, as described by Ortega et al. (2016). For each fertilization procedure, semen was used from 3 bulls; a different set of bulls was used for each replicate. After purification, sperm were counted under a microscope and diluted with IVF-TALP medium; $120 \mu \mathrm{L}$ was transferred to the fertilization plate to achieve final concentration of $1 \times 10^{6} / \mathrm{mL}$. Eighty microliters of penicillamine-hypotaurine-epinephrine solution (Ortega et al., 2016) was added to the plate to improve fertilization. Subsequently, the fertilization plate was placed in an incubator set at $38.5^{\circ} \mathrm{C}$ in a humidified atmosphere of $5 \%$ ( vol/vol) $\mathrm{CO}_{2}$ for $15 \mathrm{~h}$.

After $15 \mathrm{~h}$ of fertilization, up to 300 putative zygotes per group were transferred to a microcentrifuge tube containing $600 \mu \mathrm{L}$ of HEPES-TALP and 10,000 U/mL of hyaluronidase. Subsequently, putative zygotes (i.e., oocytes exposed to spermatozoa) were denuded by vortexing the tube for $5 \mathrm{~min}$ to remove cumulus cells. Denuded zygotes were then transferred in groups of 25 to 30 to a $45-\mu \mathrm{L}$ drop of synthetic oviduct fluid-bovine embryo 2 (SOF-BE2) covered in mineral oil (Ortega et al., 2016). Treatments were added to drops in a volume of $5 \mu \mathrm{L}$ at 10 times the final concentration. For experiment 1, treatments (final concentration) were vehicle control (i.e., $0 \mu \mathrm{g} / \mathrm{L} \mathrm{AFB}_{1}$ ) and 40, 400, and 4,000 $\mu \mathrm{g} / \mathrm{L}$ $\mathrm{AFB}_{1}$. For experiments 2 and 3 , treatments were arranged in a $2 \times 2$ factorial design with main effects of 0 or $40 \mu \mathrm{g} / \mathrm{L} \mathrm{AFB}_{1}$ and 0 or $5 \mu M$ Trolox (all final concentrations). Embryos were cultured for up to $7.5 \mathrm{~d}$ at $38.5^{\circ} \mathrm{C}$ in a humidified atmosphere of $5 \%$ (vol/vol) $\mathrm{O}_{2}, 5 \%$ (vol/vol) $\mathrm{CO}_{2}$, and the balance $\mathrm{N}_{2}$ in benchtop incubators (WTA, Carvinhos, SP, Brazil).

\section{Preparation of $A F B_{1}$}

Aflatoxin $\mathrm{B}_{1}$ in powder form (Sigma-Aldrich) was dissolved in dimethyl sulfoxide (DMSO; Sigma-Aldrich) to make $5 \mathrm{mg} / \mathrm{mL}$ stock solutions that were stored at $-20^{\circ} \mathrm{C}$. For each replicate, the treatment solutions were prepared fresh from stock solutions on the day of use by diluting the stock with SOF-BE2 culture medium. The concentration of DMSO was adjusted for each treatment so that the final concentration in the culture drop was the same for all treatments including the control 
$(0.08 \% \mathrm{vol} / \mathrm{vol}$ for experiment 1 and $0.1 \% \mathrm{vol} / \mathrm{vol}$ for experiments 2 and 3 ).

\section{Experiment 1: Concentration-Dependent Actions of $A F B_{1}$ on Development to the Blastocyst Stage}

After fertilization, putative zygotes were transferred to $45-\mu \mathrm{L}$ culture drops covered with mineral oil in groups of 30 , and $5 \mu \mathrm{L}$ of the respective treatment was added to achieve the desired concentration of $\mathrm{AFB}_{1}$. Treatments were vehicle control and 40,400, and 4,000 $\mu \mathrm{g} / \mathrm{L} \mathrm{AFB}_{1}$. Embryos were cultured until d 7.5 after fertilization. Cleavage rate and the proportion of putative zygotes that developed to the blastocyst stage were evaluated at d 3.5 and 7.5 after fertilization, respectively, using a stereomicroscope. In total, 4 replicates were performed. The total numbers of putative zygotes used were 96, 97, 95, and 95, for control and 40, 400, and $4,000 \mu \mathrm{g} / \mathrm{L} \mathrm{AFB}_{1}$, respectively.

\section{Experiment 2: Induction of ROS by $A F B_{1}$}

Putative zygotes were treated after fertilization when placed in SOF-BE2. Treatments were arranged in a $2 \times 2$ factorial design with main effects of $\mathrm{AFB}_{1}$ concentration (0 and $40 \mu \mathrm{g} / \mathrm{L})$ and Trolox (0 and 5 $\mu M)$. The concentration of Trolox was chosen because a previous study found that a $5 \mu M$ solution reduced production of ROS by preimplantation bovine embryos (Moss et al., 2009). In addition to the 4 treatments, a fifth group of embryos cultured with $5 \mu \mathrm{M}$ menadione was included as a positive control. The concentration of menadione used was reported to increase ROS production in bovine embryos (Moss et al., 2009). To measure acute production of ROS by embryos after exposure to $\mathrm{AFB}_{1}$, putative zygotes were cultured in SOF-BE2 for $3 \mathrm{~h}$ at $38.5^{\circ} \mathrm{C}$ in a humidified atmosphere of $5 \%$ ( $\mathrm{vol} /$ vol) $\mathrm{O}_{2}, 5 \%$ (vol/vol) $\mathrm{CO}_{2}$, and the balance nitrogen. After incubation, ROS production was determined as described by Ortega et al. (2016). CellRox reagent (ThermoFisher, Waltham, MA) was added to drops of putative zygotes to a final concentration of $5 \mu \mathrm{M}$. Putative zygotes were then cultured for an additional $30 \mathrm{~min}$ at $38.5^{\circ} \mathrm{C}$ as before. Embryos were then washed 3 times in $50-\mu \mathrm{L}$ drops of Dulbecco's PBS containing 2\% (wt/ vol) polyvinylpyrrolidone, placed on microscope slides in groups of up to 10 embryos, and covered with coverslips using Prolong Gold antifade reagent (Invitrogen, Carlsbad, CA). Subsequently, embryos were observed by using a Zeiss Axioplan 2 epifluorescence microscope (Zeiss, Göttingen, Germany) with a 490/525-nm excitation/emission filter to visualize fluorescence and by digital interference contrast microscopy to visualize the structure of the embryo. Digital images of each embryo were captured using AxioVision software (version 4.8.2, Zeiss, Peabody, MA) at a magnification of $40 \times$. Quantification of fluorescent intensity was determined by manually tracing the perimeter of the embryo on the computer screen and using the software to calculate average pixel intensity within the boundaries of the embryo. In total, 2 replicates were performed. The total number of putative zygotes per treatment ranged from 13 to 19 . In addition, 12 putative zygotes were treated with menadione.

\section{Experiment 3: Effectiveness of Trolox in Alleviating Developmental Impacts of $A F B_{1}$}

The experiment used a $2 \times 2$ factorial design with $\mathrm{AFB}_{1}$ concentration $(0$ and $40 \mu \mathrm{g} / \mathrm{L})$ and Trolox concentration $(0$ and $5 \mu M)$ as main effects. After fertilization, putative zygotes were placed in SOF-BE2 containing appropriate treatments and incubated at $38.5^{\circ} \mathrm{C}$ in a humidified atmosphere of $5 \%(\mathrm{vol} / \mathrm{vol}) \mathrm{O}_{2}, 5 \%$ (vol/ vol) $\mathrm{CO}_{2}$, and the balance nitrogen for $7.5 \mathrm{~d}$. Cleavage and the cell number of each embryo were estimated by microscopic evaluation at d 4 after fertilization, and blastocyst formation was determined at d 7. A total of 6 experimental replicates were performed. The total number of putative zygotes per treatment ranged from 160 to 195.

\section{Statistical Analysis}

The percentages of oocytes undergoing cleavage; cleaved embryos developing to the $\geq 3$-cell, $\geq 5$-cell, and $\geq 9$-cell stages; and oocytes and cleaved embryos becoming blastocysts were calculated for each replicate. Treatment effects were analyzed using the GLIMMIX procedure of SAS v 9.4 (SAS Institute, Cary, NC). For experiment 1 , the statistical model included the fixed effect of treatment and random effect of replicate. Preplanned orthogonal contrasts were conducted to compare the differences between various levels of treatment as follows: control vs. $40 \mu \mathrm{g} / \mathrm{L} \mathrm{AFB}_{1}, 400$ vs. 4,000 $\mu \mathrm{g} / \mathrm{L} \mathrm{AFB}_{1}$, and low $\mathrm{AFB}_{1}$ vs. high $\mathrm{AFB}_{1}$ (control and $40 \mu \mathrm{g} / \mathrm{L} \mathrm{AFB}_{1}$ vs. 400 and $4,000 \mu \mathrm{g} / \mathrm{L} \mathrm{AFB}_{1}$ ). For experiments 2 and 3 , the model included fixed effects of $\mathrm{AFB}_{1}$ and Trolox and their interaction as well as the random effect of replicate. Data on ROS production in experiment 2 were also analyzed by GLIMMIX except that embryo was the experimental unit. In all cases, significance was declared at $P \leq 0.05$, while a tendency was regarded as $0.05<P \leq 0.10$. 


\section{RESULTS}

\section{Experiment 1: Concentration-Dependent Actions of $A F B_{1}$ on Development to the Blastocyst Stage}

Results are shown in Figure 1. Overall, the effect of treatment on cleavage tended to be significant $(P<$ $0.10)$. Analysis using orthogonal contrasts revealed that
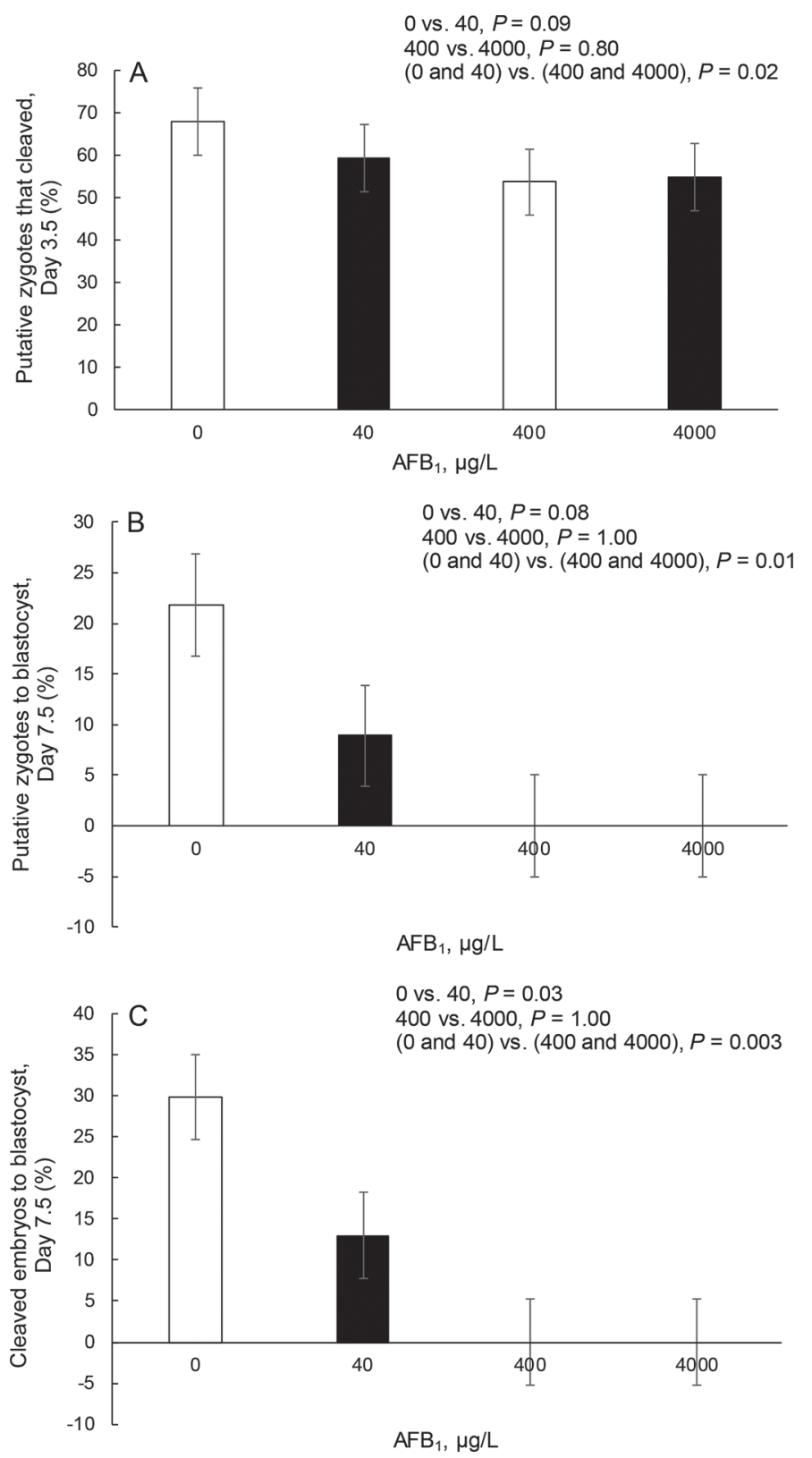

Figure 1. Effects of culturing putative zygotes after fertilization with various concentrations of aflatoxin $\mathrm{B}_{1}\left(\mathrm{AFB}_{1}\right)$ on cleavage $(\mathrm{A})$ and development to the blastocyst stage $(\mathrm{B}, \mathrm{C})$ in experiment 1 . Data are $\mathrm{LSM} \pm$ SEM.
$40 \mu \mathrm{g} / \mathrm{L} \mathrm{AFB}_{1}$ tended to reduce $(P=0.09)$ cleavage compared with the control and that 400 and $4,000 \mu \mathrm{g} / \mathrm{L}$ $\mathrm{AFB}_{1}$ reduced cleavage compared with lower concentrations $(P=0.02)$. We observed no difference between 400 and $4,000 \mu \mathrm{g} / \mathrm{L} \mathrm{AFB}_{1}$. An overall effect of treatment was found for the percentage of putative zygotes and cleaved embryos that developed to the blastocyst stage $(P=0.01)$. Using orthogonal contrasts, $40 \mu \mathrm{g} / \mathrm{L}$ $\mathrm{AFB}_{1}$ reduced the percentage of putative zygotes $(P$ $=0.07)$ and percentage of cleaved embryos $(P=0.03)$ that became blastocysts. Similarly, blastocyst development, whether expressed as percentage of putative zygotes $(P=0.01)$ or cleaved embryos $(P=0.03)$, was lower for 400 and $4,000 \mu \mathrm{g} / \mathrm{L} \mathrm{AFB}_{1}$ than either control or $40 \mu \mathrm{g} / \mathrm{L} \mathrm{AFB}_{1}$. In fact, no embryos cultured in 400 or $4,000 \mu \mathrm{g} / \mathrm{L} \mathrm{AFB}_{1}$ became a blastocyst. As a result, no significant difference existed between 400 and 4,000 $\mu \mathrm{g} / \mathrm{L} \mathrm{AFB}_{1}$.

\section{Experiment 2: Induction of ROS by Aflatoxin}

Representative images of ROS production are shown in Figure 2. As expected, the positive control menadione increased production of ROS. In addition, ROS production was increased by $40 \mu \mathrm{g} / \mathrm{L}$ aflatoxin. Treatment with Trolox alone did not affect ROS production, but Trolox reduced ROS production in embryos cultured with $\mathrm{AFB}_{1}$.

Results of quantification of ROS production are presented in Figure 3. Production of ROS was affected by $\mathrm{AFB}_{1}(P=0.004)$ and the interaction between $\mathrm{AFB}_{1}$ and Trolox $(P=0.03)$. These effects reflect increased ROS production caused by $40 \mu \mathrm{g} / \mathrm{L} \mathrm{AFB}_{1}$ and inhibition of this action of $\mathrm{AFB}_{1}$ by Trolox.

\section{Experiment 3: Effectiveness of Trolox in Alleviating Developmental Impacts of AFB}

Treatment with $40 \mu \mathrm{g} / \mathrm{L} \mathrm{AFB}_{1}$ did not affect cleavage but reduced the percentage of putative zygotes and cleaved embryos becoming blastocysts $(P<0.05$ for both variables) (Figure 4 ). The main effect of Trolox and the effect of the interaction between aflatoxin and Trolox were not significant $(P>0.10)$ for any variable.

To better understand the stage of development at which $\mathrm{AFB}_{1}$ blocked development, we evaluated the percentage of cleaved embryos at $\mathrm{d} 4$ that had advanced to the $>3$-cell stage, 5 -cell stage, or 9-cell stage (Figure $5)$. The percentage of cleaved embryos that developed to $\geq 3$ - or $\geq 5$-cell stages was not affected by $\mathrm{AFB}_{1}$, Trolox, or their interaction. In contrast, the percentage of cleaved embryos that developed to $\geq 9$-cell stage tended to be reduced $(P=0.09)$ by $\mathrm{AFB}_{1}$. 


\section{Trolox (-)}
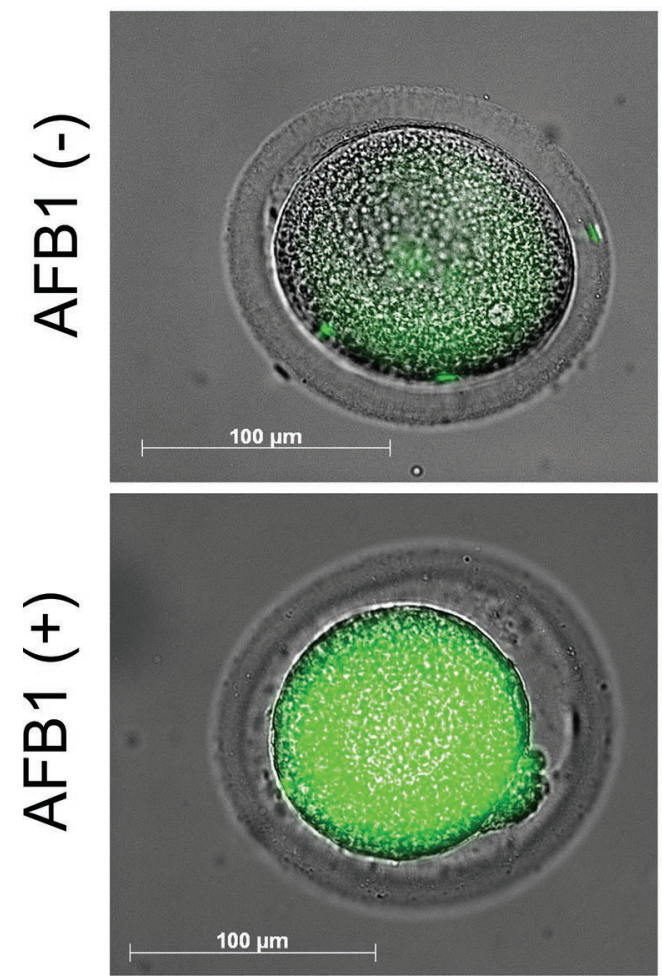

Trolox (+)
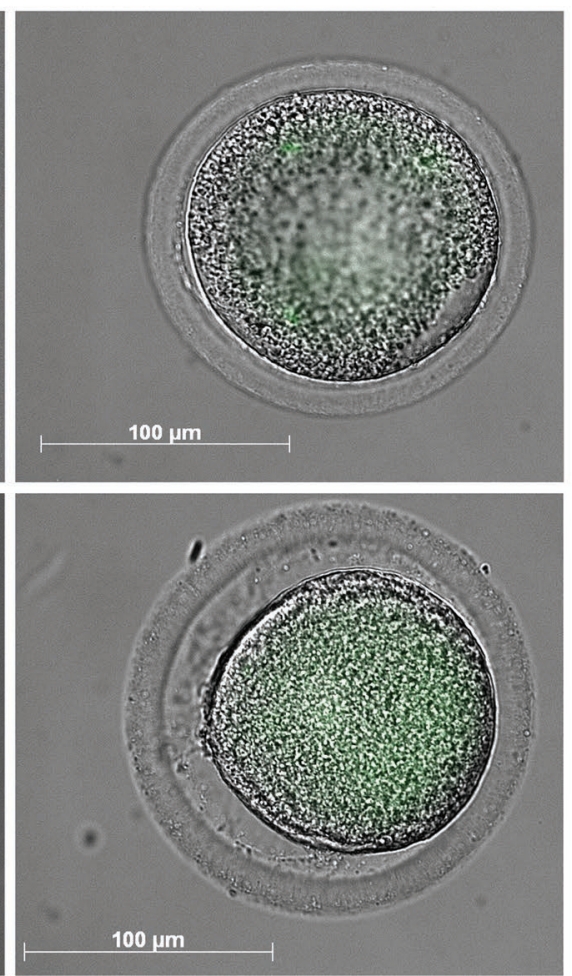

Menadione (positive control)

Figure 2. Representative images of effects of aflatoxin $\mathrm{B}_{1}\left(\mathrm{AFB}_{1}\right)$ and $5 \mu M$ Trolox on reactive oxygen species production by putative zy-

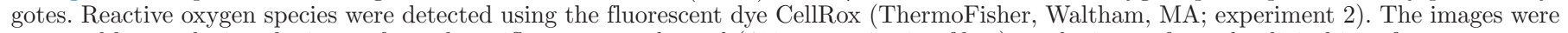

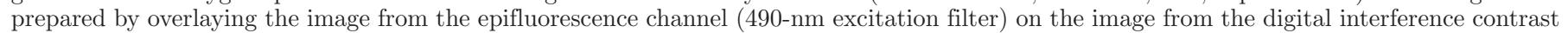
channel.

\section{DISCUSSION}

Results of the present experiment indicate that $\mathrm{AFB}_{1}$ can reduce competence of embryos to cleave and become blastocysts. Negative effects of $\mathrm{AFB}_{1}$ were seen at concentrations as low as $40 \mu \mathrm{g} / \mathrm{L}$. Although higher concentrations of 400 and $4,000 \mu \mathrm{g} / \mathrm{L}$ completely blocked development of embryo, these concentrations are not likely to occur in animals. An experiment in which levels of ROS were measured indicated that one cause for the reduction in development caused by $\mathrm{AFB}_{1}$ is increased production of ROS. However, other mechanisms are also likely to be involved because treatment with the antioxidant Trolox, although reducing ROS production, did not reverse the negative effects of aflatoxin on embryonic development.

It is well known that excessive production of ROS can compromise development of the preimplantation embryo (Soto et al., 2003; Moss et al., 2009; Yazaki et al., 2013) and that $\mathrm{AFB}_{1}$ can induce ROS production in several cell types (Shen et al., 1996; Mehrzad et al., 2011; Liu and Wang, 2016) including the pre- implantation embryo (Shin et al., 2018). The fact that Trolox did not prevent the negative effect of $\mathrm{AFB}_{1}$ on development to the blastocyst stage despite reducing ROS production indicates that $\mathrm{AFB}_{1}$ causes more than one insult to the developing embryo. In addition, $\mathrm{AFB}_{1}$ possibly interferes with embryonic genome activation, which occurs at the 8-cell stage in cattle (Graf et al., 2014). This possibility is surmised because $\mathrm{AFB}_{1}$ did not affect the percentage of cleaved embryos developing to the $\geq 5$-cell stage but tended to reduce the number that became 9 cells or more. Moreover, exo- and endo-epoxides of $\mathrm{AFB}_{1}$ can react with DNA and lead to DNA mutations (McCullough and Lloyd, 2019). In the pig embryo, exposure to $\mathrm{AFB}_{1}$ increased DNA damage and decreased DNA repair (Shin et al., 2018).

An important question is whether embryos from cows fed aflatoxin-contaminated feeds are exposed to $\mathrm{AFB}_{1}$ at concentrations high enough to compromise embryonic development. Concentrations of $\mathrm{AFB}_{1}$ in uterine fluid have not been measured, and large differences in $\mathrm{AFB}_{1}$ accumulation exist between tissues. For example, concentrations of $\mathrm{AFB}_{1}$ in one cow fed aflatoxin-con- 


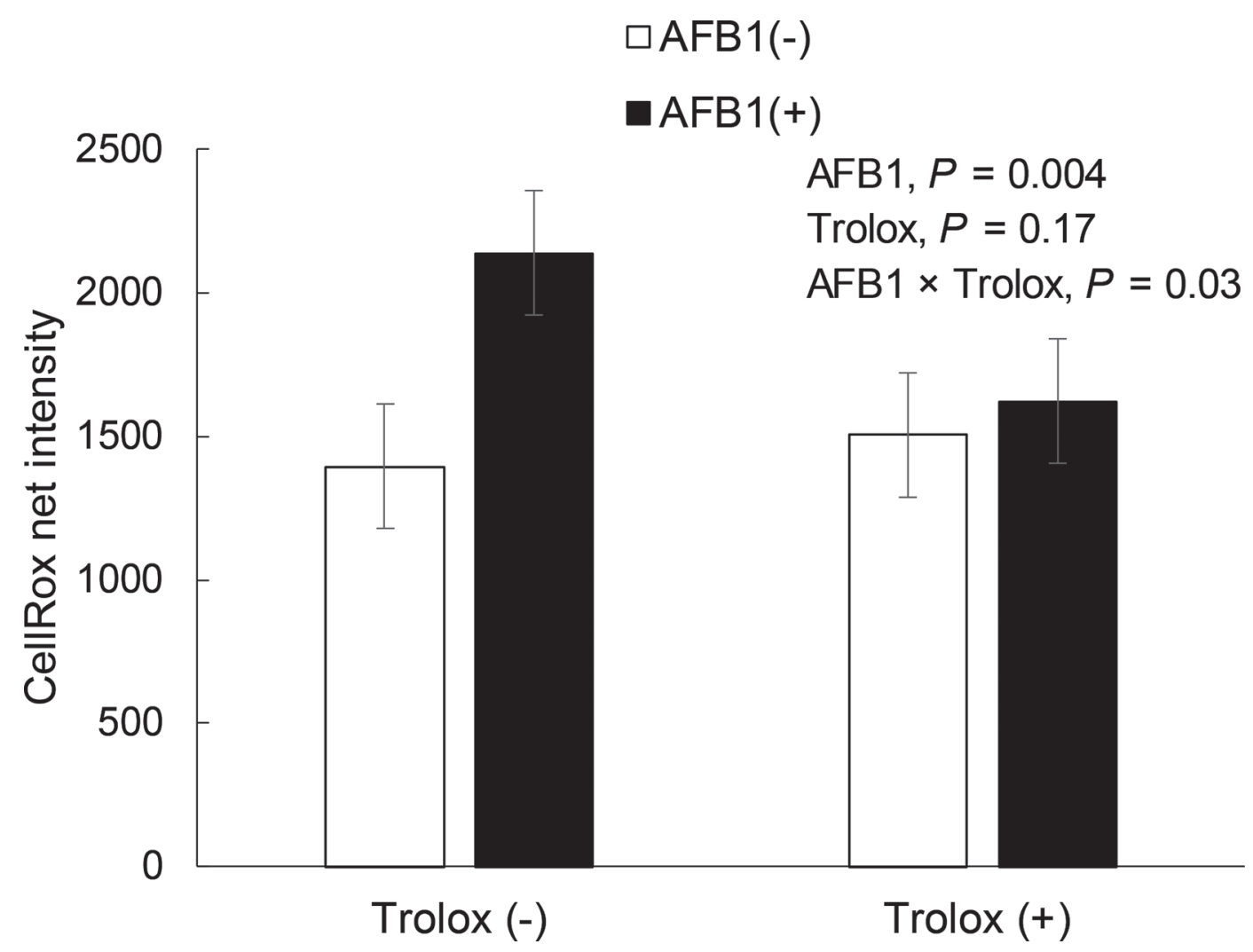

Figure 3. Production of reactive oxygen species (CellRox net intensity; ThermoFisher, Waltham, MA) of putative zygotes as affected by incubation with $40 \mu \mathrm{g} / \mathrm{L}$ aflatoxin $\mathrm{B}_{1}\left(\mathrm{AFB}_{1}\right)$ and $5 \mu M$ Trolox (experiment 2). Data are LSM $\pm \mathrm{SEM}$.

taminated feed ranged from $7.1 \mu \mathrm{g} / \mathrm{kg}$ in liver, $2.0 \mu \mathrm{g} /$ $\mathrm{kg}$ in gallbladder, $1.3 \mu \mathrm{g} / \mathrm{kg}$ in kidney, and $0.3 \mu \mathrm{g} / \mathrm{kg}$ in skeletal muscle. Further, AFM1, which is also a potent hepatotoxin and carcinogen (Green et al., 1982), ranged from $56.6 \mu \mathrm{g} / \mathrm{kg}$ in the kidney, $6.1 \mu \mathrm{g} / \mathrm{kg}$ in the liver, and $24.5 \mu \mathrm{g} / \mathrm{kg}$ in the mammary gland (Stubblefield et al., 1983). Concentrations of $\mathrm{AFB}_{1}$ in the blood of a steer treated with $0.8 \mathrm{mg} \mathrm{AFB}_{1} / \mathrm{kg}$ of $\mathrm{BW}$ peaked at 21 $\mu \mathrm{g} / \mathrm{L}$ (Cook et al., 1986), whereas peak concentrations in the blood of cows fed aflatoxin-contaminated corn was $0.034 \mu \mathrm{g} / \mathrm{L}$ (Gallo et al., 2008). A survey of lactating cows in Tunisia found that $84 \%$ of 58 feed samples and $55 \%$ of 56 plasma samples contained detectable concentrations of $\mathrm{AFB}_{1}$ (Abbès et al., 2012). For the positive samples, the average concentrations of $\mathrm{AFB}_{1}$ were 18.7 $\mu \mathrm{g} / \mathrm{kg}$ in feed and $7.0 \mu \mathrm{g} / \mathrm{kg}$ in blood plasma. Only $10 \%$ of positive plasma samples had concentrations of $\mathrm{AFB}_{1}$ $>10 \mu \mathrm{g} / \mathrm{kg}$. Taken together, the evidence suggests that the lowest concentration of $\mathrm{AFB}_{1}$ tested here, $40 \mu \mathrm{g} / \mathrm{L}$, likely represents a concentration of $\mathrm{AFB}_{1}$ that is higher than that typically experienced by cows fed aflatoxincontaminated feed. However, embryos in vivo are likely to be exposed to a mixture of aflatoxin metabolites including $\mathrm{AFB}_{1}$ and $\mathrm{AFM}_{1}$. Additional experiments to measure concentrations of $\mathrm{AFB}_{1}$ and $\mathrm{AFM}_{1}$ in uterine fluid of cows fed aflatoxin-contaminated feed can provide useful information for future experiments to evaluate direct effects of aflatoxins on embryonic development. It should be noted, however, that $\mathrm{AFB}_{1}$ has been reported (Liu et al., 2015) to reduce development of pig embryos at a concentration of $1 \mathrm{n} M$ (i.e., 0.3 $\mu \mathrm{g} / \mathrm{L}$ ), so even low amounts of aflatoxin contamination may lead to embryotoxicity.

In conclusion, our results indicate that $\mathrm{AFB}_{1}$ can reduce competence of oocytes to cleave and become blastocysts. The mechanism of action of $\mathrm{AFB}_{1}$ involves ROS formation as well as other effects because antioxidant treatment was not sufficient to block the antidevelopmental effects of aflatoxin. Future experiments should be performed to determine concentrations of $\mathrm{AFB}_{1}$ in uterine fluid of cows fed aflatoxin-contaminated feeds to determine concentrations of $\mathrm{AFB}_{1}$ that are physiologically relevant to the embryo.

\section{ACKNOWLEDGMENTS}

Authors thank Elizabeth Jannaman (University of Florida) for support of the IVF laboratory, Eddie Cum- 
$\square$ AFB1 (-)

AFB1 (+)
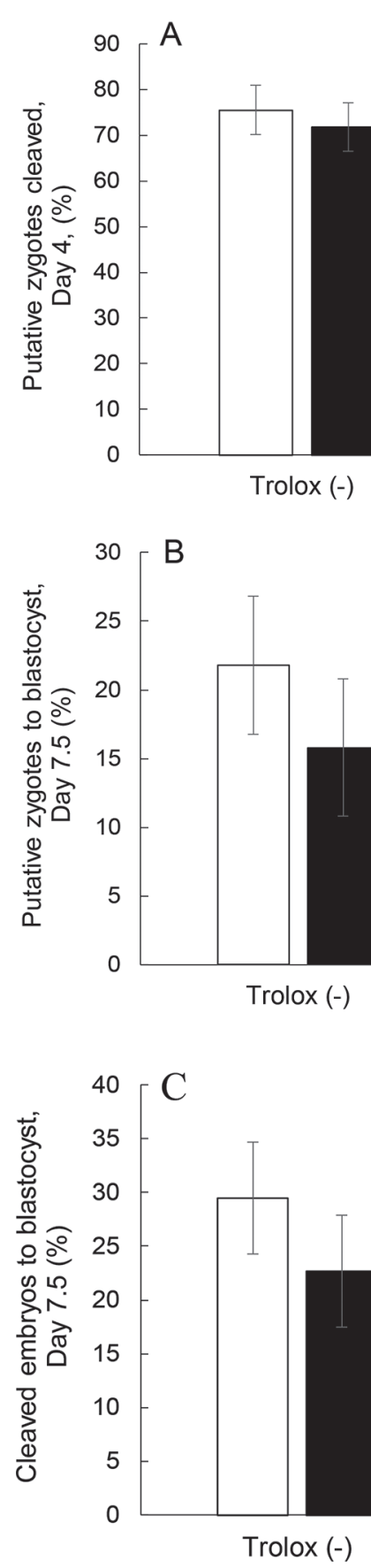

Figure 4. Effects of culturing putative zygotes after fertilization with $40 \mu \mathrm{g} / \mathrm{L}$ aflatoxin $\mathrm{B}_{1}\left(\mathrm{AFB}_{1}\right)$ in the presence or absence of $5 \mu \mathrm{M}$ Trolox on oocyte cleavage (A) and subsequent development to the blastocyst stage $(\mathrm{B}, \mathrm{C})$ in experiment 3 . Data are $\mathrm{LSM} \pm \mathrm{SEM}$.

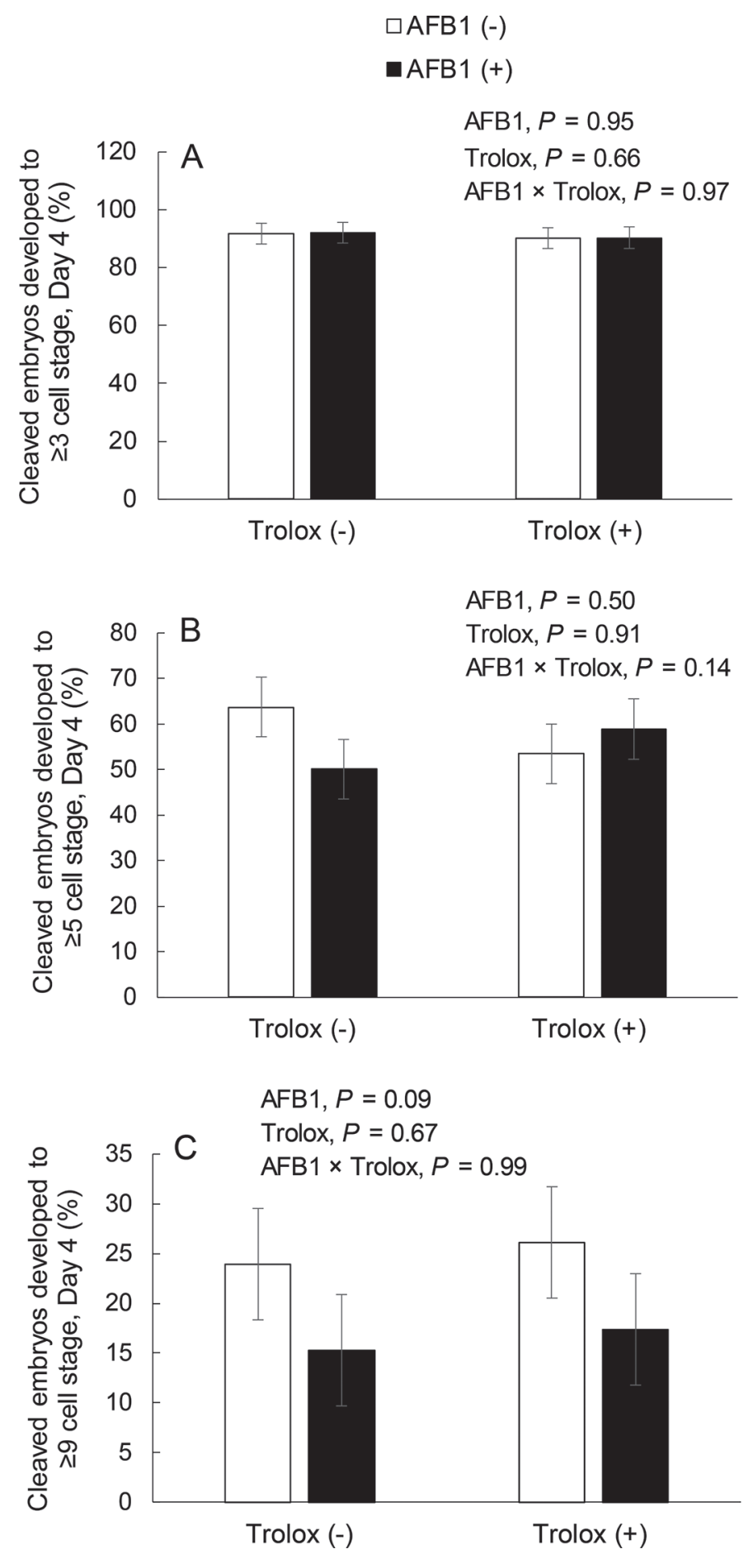

Figure 5. Effects of culturing putative zygotes after fertilization with $40 \mu \mathrm{g} / \mathrm{L}$ aflatoxin $\mathrm{B}_{1}\left(\mathrm{AFB}_{1}\right)$ in the presence or absence of $5 \mu M$ Trolox on the proportion of cleaved embryos reaching specific developmental stages at d 4 (experiment 3). Treatment with $40 \mu \mathrm{g} / \mathrm{L} \mathrm{AFB}_{1}$ did not reduce the percentage of cleaved embryos developing to the 3 -cell (A) or 5 -cell (B) stage but reduced $(P=0.09)$ the percentage of cleaved embryos that developed to the 9-cell stage (C). Neither Trolox nor the interaction had a significant effect. Data are LSM \pm SEM. 
mings (University of Florida) for procuring ovaries, and Florida Beef (Wauchula, FL) for allowing access to abattoir material. We also thank I. M. Ogunade (Kentucky State University) and K. Arriola (University of Florida) for reading a draft of the manuscript. Research was supported by funds from the L. E. "Red" Larson Endowment. Y. Jiang was supported by a fellowship from the University of Florida.

\section{REFERENCES}

Abbès, S., J. B. Salah-Abbès, Y. Bouraoui, S. Oueslati, and R. Oueslati. 2012. Natural occurrence of aflatoxins $\left(B_{1}\right.$ and $\left.M_{1}\right)$ in feed, plasma and raw milk of lactating dairy cows in Beja, Tunisia, using ELISA. Food Addit. Contam. Part B Surveill. 5:11-15.

Cook, W. O., J. L. Richard, G. D. Osweiler, and D. W. Trampel. 1986. Clinical and pathologic changes in acute bovine aflatoxicosis: $\mathrm{Ru}-$ men motility and tissue and fluid concentrations of aflatoxins B1 and M1. Am. J. Vet. Res. 47:1817-1825.

Frisvad, J. C., P. Skouboe, and R. A. Samson. 2005. Taxonomic comparison of three different groups of aflatoxin producers and a new efficient producer of aflatoxin B1, sterigmatocystin and 3-O-methylsterigmatocystin, Aspergillus rambellii sp. nov. Syst. Appl. Microbiol. 28:442-453.

Gallo, A., M. Moschini, and F. Masoero. 2008. Aflatoxins absorption in the gastro-intestinal tract and in the vaginal mucosa in lactating dairy cows. Ital. J. Anim. Sci. 7:53-63.

Graf, A., S. Krebs, V. Zakhartchenko, B. Schwalb, H. Blum, and E. Wolf. 2014. Fine mapping of genome activation in bovine embryos by RNA sequencing. Proc. Natl. Acad. Sci. USA 111:4139-4144.

Green, C. E., D. W. Rice, D. P. H. Hsieh, and J. L. Byard. 1982. The comparative metabolism and toxic potency of aflatoxin B1 and aflatoxin M1 in primary cultures of adult-rat hepatocytes. Food Chem. Toxicol. 20:53-60.

Han, R. W., N. Zheng, J. Q. Wang, Y. P. Zhen, X. M. Xu, and S. L. Li. 2013. Survey of aflatoxin in dairy cow feed and raw milk in China. Food Control 34:35-39.

Komsky-Elbaz, A., M. Saktsier, and Z. Roth. 2018. Aflatoxin B1 impairs sperm quality and fertilization competence. Toxicology 393:42-50.

Liu, J., Q. C. Wang, J. Han, B. Xiong, and S. C. Sun. 2015. Aflatoxin $\mathrm{B} 1$ is toxic to porcine oocyte maturation. Mutagenesis 30:527-535.

Liu, Y., and W. Wang. 2016. Aflatoxin B1 impairs mitochondrial functions, activates ROS generation, induces apoptosis and involves
Nrf2 signal pathway in primary broiler hepatocytes. Anim. Sci. J. 87:1490-1500.

McCullough, A. K., and R. S. Lloyd. 2019. Mechanisms underlying aflatoxin-associated mutagenesis-Implications in carcinogenesis. DNA Repair (Amst.) 77:76-86.

Mehrzad, J., G. Klein, J. Kamphues, P. Wolf, N. Grabowski, and H. J. Schuberth. 2011. In vitro effects of very low levels of aflatoxin B1 on free radicals production and bactericidal activity of bovine blood neutrophils. Vet. Immunol. Immunopathol. 141:16-25.

Moss, J. I., E. Pontes, and P. J. Hansen. 2009. Insulin-like growth factor-1 protects preimplantation embryos from anti-developmental actions of menadione. Arch. Toxicol. 83:1001-1007.

Nimse, S. B., and D. Pal. 2015. Free radicals, natural antioxidants, and their reaction mechanisms. RSC Advances 5:27986-28006.

Ogunade, I. M., C. Martinez-Tuppia, O. C. M. Queiroz, Y. Jiang, P. Drouin, F. Wu, D. Vyas, and A. T. Adesogan. 2018. Silage review: Mycotoxins in silage: Occurrence, effects, prevention, and mitigation. J. Dairy Sci. 101:4034-4059.

Ortega, M. S., N. A. S. Rocha-Frigoni, G. Z. Mingoti, Z. Roth, and P. J. Hansen. 2016. Modification of embryonic resistance to heat shock in cattle by melatonin and genetic variation in HSPA1L. J. Dairy Sci. 99:9152-9164.

Rodrigues, I., and K. Naehrer. 2012. A three-year survey on the worldwide occurrence of mycotoxins in feedstuffs and feed. Toxins (Basel) 4:663-675.

Shen, H. M., C. Y. Shi, Y. I. Shen, and C. N. Ong. 1996. Detection of elevated reactive oxygen species level in cultured rat hepatocytes treated with aflatoxin B1. Free Radic. Biol. Med. 21:139-146.

Shin, K. T., J. Guo, Y. J. Niu, and X. S. Cui. 2018. The toxic effect of aflatoxin B1 on early porcine embryonic development. Theriogenology 118:157-163.

Soto, P., R. P. Natzke, and P. J. Hansen. 2003. Identification of possible mediators of embryonic mortality caused by mastitis: Actions of lipopolysaccharide, prostaglandin F2, and the nitric oxide generator, sodium nitroprusside dihydrate, on oocyte maturation and embryonic development in cattle. Am. J. Reprod. Immunol. 50:263-272.

Stubblefield, R. D., A. C. Pier, J. L. Richard, and O. L. Shotwell. 1983. Fate of aflatoxins in tissues, fluids, and excrements from cows dosed orally with aflatoxin B1. Am. J. Vet. Res. 44:1750-1752.

Takahashi, T., K. Sasaki, T. Somfai, T. Nagai, N. Manabe, and K. Edashige. 2016. N, N-Dimethylglycine decreases oxidative stress and improves in vitro development of bovine embryos. J. Reprod. Dev. 62:209-212.

Yazaki, T. Y. Hiradate, Y. Hoshino, K. Tanemura, and E. Sato. 2013. L-carnitine improves hydrogen peroxide-induced impairment of nuclear maturation in porcine oocytes. Anim. Sci. J. 84:395-402. 